At present there is insufficient information on either the nature or the magnitude of this "substantial" benefit to allow implementation of a fully rational policy. While the compromise proposed by Brill and others may suffice as a temporary measure, a more permanent decision will have to await the collection of information on, for example, the yield of abnormal findings from common radiological procedures; the yield of abnormal findings within certain high risk categories (such as preoperative chest radiography in the elderly); measurements of the frequency with which the discovery of a positive or negative radiological finding influences subsequent management of the patient; and the degree of additional benefit conferred on the patient by such a change. Given information of this kind, it should be possible to draw up guidelines which will allow a more rational use to be made of the existing diagnostic radiological facilities. Such guidelines are considered as being of great importance by the Royal College of Radiologists, and there are now proposals to establish a National Multicentre Study to collect the necessary information.
AMR's part in the work was done during a student elective attachment to the Department of Community Medicine.

\section{References}

${ }^{1}$ Kerr, I H, British fournal of Anaesthesia, 1974, 46, 558.

2 Ashley, J H H, Pasker, P, and Beresford, J C, Lancet, 1972, 1, 890.

${ }^{3}$ Sagel, S S, et al, New England fournal of Medicine, 1974, 291, 1001.

${ }^{4}$ Roberts, F, and Schopfner, C E, American fournal of Roentgenology, Radium Therapy and Nuclear Medicine, 1972, 114, 231.

${ }^{5}$ Bull, J W D, and Zilkha, K J, British Medical fournal, 1968, 4, 569.

${ }^{6}$ Brill, P W, Ewing, M L, and Dunn, A H, Paediatrics, 1973, 52, 125.

${ }^{7}$ Kreel, L, et al, British Medical fournal, 1974, 4, 33.

${ }^{8}$ Jones, G R, and Roberts, C J, to be published.

9 Medical Research Council Committee on the Aetiology of Chronic Bronchitis, Lancet, 1975, 1, 775.

10 Rose, G, Blackburn, H, Cardiovascular Survey Methods. Geneva, World Health Organisation, 1968.

${ }^{11}$ Department of Health and Social Security. Code of Practice for the Protection of Persons Against Ionising Radiations arising from Medical and Dental Use. London, HMSO, 1972.

12 Simon, G, Clinical Radiology, 1975, 26, 429.

\title{
Can geriatrics survive?
}

\author{
J C LEONARD
}

British Medical fournal, 1976, 1, 1335-1336

\section{Summary}

Geriatrics has consistently failed to attract enough staff, and hence geriatric units often cannot provide a full service for the elderly. Meanwhile beds in general medical units may be blocked by elderly patients. This division between geriatric and medical units is arbitrary and wasteful. There are no clinical processes or techniques unique to geriatrics, which is probably why the specialty is unattractive; few doctors want to confine their attention only to the elderly. Geriatrics as a separate specialty should therefore be largely abandoned and the care of the elderly reintegrated into general medicine.

\section{Introduction}

The paper by McArdle et $a l^{1}$ on the problem of long-stay patients in acute medical wards has clearly provoked the ire of geriatricians,,$^{23}$ some of whom have suggested that this can best be solved by transferring large numbers of beds from the care of general physicians to that of the geriatricians. The problem that they describe is clearly widespread and causes much illfeeling between medical and geriatric units. In many areas the admission to hospital of elderly patients who fall acutely ill is haphazardly divided between medical and geriatric units. The

University Hospital of South Manchester, Manchester M20 8LR J C LEONARD, MD, FRCP, consultant physician

medical units are usually reasonably well staffed, but there is often reluctance to admit certain elderly patients because of the well-founded fear that large numbers of beds will be blocked for many months at a time. In my own general medical unit about a third of the women inpatients are awaiting transfer, either to chronic sick wards or to accommodation provided for those in need of care and attention under part III of the National Assistance Act 1948. By contrast, geriatric units are often poorly staffed and are consequently often unable to offer a full service to the elderly. The present arrangements seem to me to be arbitrary, inefficient, unsatisfactory, and uneconomic.

One solution, clearly favoured by some geriatricians, is a massive takeover of general medicine by geriatrics. This conveniently ignores the fact that it has proved impossible to staff geriatric units adequately with British-trained doctors. Although it is over 20 years since the first consultant appointments in geriatric medicine were made, the specialty has consistently failed to attract enough junior and senior medical staff. A recent review ${ }^{4}$ stated that $60^{\circ} \%$ of senior registrars in geriatrics are from overseas, and already $30 \%$ of consultants are from overseas. The author comments that "high prospects are apparently not sufficient to attract doctors in this specialty." If, as is generally expected, the supply from overseas declines, geriatrics will face a further severe crisis in manpower.

\section{Structure of medical care}

Brocklehurst maintains that "The principles of geriatric medicine fall into two main groups. First, those of clinical presentation which are unique to the elderly and different from clinical medicine in younger people; second, the structure of medical care which is specifically adapted to the needs of this group." ' ${ }^{5}$ There is, however, no clinical presentation of illness 
unique to the elderly; even the multiple pathology beloved by the geriatricians is common enough at the age of 60 or even earlier, and geriatrics therefore shades off imperceptibly into general medicine. Some patients of 55 are more "geriatric" than others of 80 . This lack of definition of the subject is probably the basic reason why geriatrics has failed to establish itself as an attractive discipline. Surgical conditions in the elderly are common and have important differences in presentation from those in younger patients; yet no one suggests that a specialty of geriatric surgery should be created. Why therefore is geriatric medicine necessary as a separate discipline ? One suspects that the specialty has been devised more for administrative and political reasons than for clinical ones. It is in fact the only specialty currently recognised that does not possess a firm foundation in clinical processes or techniques unique to that specialty. The "structure of medical care" required for the elderly raises the question whether the structure can be adequately staffed.

\section{Staffing}

The problem of staffing geriatric units centres entirely on the fact that relatively few doctors want to confine their clinical attention solely to elderly patients. Virtually all physicians, both senior and junior, are fully prepared to look after many elderly patients, but naturally enough they like to look after younger ones as well. The average age of the patients in many acute medical wards is probably not very different from that of those admitted to an acute geriatric ward. Junior medical staff working in general medical units see many elderly patients, and every physician accepting general medical emergencies acquires plentiful experience in the medicine of old age.

To ease their staffing problem, there has been great pressure from geriatric units in many areas for linked appointments between geriatrics and general medicine at senior house officer and other levels. In general, this has been resisted by general physicians; many no doubt feel that the calibre of applicants will fall if the appointment is linked with geriatrics, and I know of one experiment in a teaching hospital that is being abandoned because this has been found to be so. Resistance to linked appointments comes, however, not only from "reactionary" physicians but even more from junior staff working, or hoping to work, in general medicine; they feel, rightly in my view, that additional clinical experience in geriatric units is unnecessary and if made compulsory would be intensely unpopular. It is unacceptable that geriatrics should survive only by permanent infusions of unwilling junior staff conscripted from another specialty.

\section{Reintegration}

This prompts the question whether the maintenance of geriatrics as a separate discipline is the best way of providing medical care for the ever-increasing numbers of elderly patients. One solution to this problem, which should be explored, would be the reintegration of geriatrics into general medicine by abolishing geriatrics as a separate specialty. In view of the similarity of the acute inpatient workload there seems no justification for separate general medical and acute geriatric units. Physicians accepting a general medical intake and their junior medical staff will be at least as competent as the staff of geriatric units to deal with acute illness in the elderly and assess elderly patients with long-term problems or who are brought into hospital for "social" reasons. I therefore suggest that all future appointments for consultant physicians, both in teaching and in non-teaching hospitals, should include a specified commitment to the care of the elderly so that geriatrics can be reintegrated into general medicine, where it properly belongs. This commitment should be in addition to a recognised interest in a medical subspecialty such as cardiology, respiratory disease, gastroenterology, etc. Experience of the multiple pathology of the elderly would be an excellent corrective to the blinkered approach fostered by over-specialisation.

If the work of the existing geriatric units was thus brought into the fold of general medicine the intractable problem of junior medical staffing would be solved. It might be decided that no further consultant appointments in "pure" geriatrics should be made; or, alternatively, a few centres might be preserved to cater for the relatively few doctors who really want to confine their clinical work to the care of the elderly and to act as centres for teaching and clinical research. Existing geriatricians should be brought into general medical units in ways which would doubtless vary from district to district. Geriatricians with particular interest in rehabilitation might be integrated into the specialty of rheumatology and rehabilitation. In some districts physicians might decide to divide their geriatric responsibilities on a rotational basis; others might prefer to reserve some sessions each week for this work. I foresee great advantages in the same group of physicians having control over both the acute and long-stay wards; this would go a long way to solving the problem of "blocked beds." The day-to-day care of patients in the long-stay wards should be the responsibility not of junior hospital staff but of general practitioners or clinical assistants employed on a sessional basis, with a consultation physician readily available on request. It is important that other professional staff working in geriatric units, especially nurses and social workers, should also be reintegrated into the general medical services.

\section{Success or failure?}

It will no doubt be objected that geriatrics emerged precisely because the elderly were not being properly cared for by earlier generations of physicians. Twenty years ago this may have been so, but events have sadly proved that geriatrics as a separate specialty is not viable because it cannot recruit enough staff of adequate calibre. If geriatricians wish to preserve their specialty as a separate discipline the onus is on them to show that they can attract enough British-trained staff on their own merits. If this cannot be done then geriatrics should, like respiratory medicine, be reintegrated into general medicine. Such a reintegration should be regarded, not as a failure of geriatrics, but, paradoxically, as a success. As a result of the efforts of the present generation of geriatricians the needs of the elderly have become clarified, and indeed great progress has been made towards meeting these needs. It is now time for all physicians to share in this work.

\section{References \\ ${ }^{1}$ McArdle, C, Wylie, J C, and Alexander, W D, British Medical fournal, $1975,4,568$. \\ ${ }^{2}$ British Medical fournal, 1975, 4, 704. \\ ${ }^{3}$ British Medical fournal, 1976, 1, 40. \\ - British Medical fournal, 1976, 1, 174. \\ 5 Brocklehurst, J C, Hospital Update, 1975, 1, 435.}

Are vegetarians more prone to depression than those who take a mixed diet?

The main danger of a vegetarian diet is in the lack of minerals and certain vitamins. If vegetarians are careful to maintain a balanced diet which includes fresh fruits and green vegetables and to avoid too miuch packaged food, there should be little danger of such dietetic insufficiency. Nevertheless there are conditions such as Wernicke's syndrome associated with thiamine deficiency in which mental changes occur. These changes, however, give a very mixed picture including depression, irritability, quarrelsomeness, and memory loss. It would appear, therefore, that in this case, in which only depression is mentioned, the association between vegetarian diet and periodic depression is probably coincidental. 